\title{
INTUSSUSCEPÇÃO ILEOCÓLICA ASSOCIADA A TORÇÃO MESENTÉRICA EM UM CÃO: RELATO DE CASO
}

\author{
Larissa Correa Hermeto", Santiago Benites Pádua1, Diogo Helney Freire², Douglas \\ Rodrigo $\mathrm{Mattei}^{3}$
}

\author{
1 UNESP Jaboticabal \\ 2 ULTRAVET - Diagnósticos Veterinários \\ ${ }^{3}$ Faculdade Anhanguera de Doutorados \\ Correspondência: Larissa Correa Hermeto: larissa_hermeto@yahoo.com.br
}

\begin{abstract}
RESUMO: A torção mesentérica é uma doença rara no cão, sendo mais comum o acometimento em animais de grande porte. Os principais sinais clínicos observados são agudos, como prostação e distensão abdominal, que evoluem para o estado de choque e óbito. O presente trabalho relata a torção de mesentério em um cão, que deu entrada ao atendimento veterinário apresentando dor abdominal aguda generalizada de início súbito. Ao exame físico detectou-se sinais de abdômen agudo, temperatura retal de 35 graus Celsius, desidratação moderada, mucosas congestas e prostração. Foi instituída terapia emergencial e solicitado exame ultrassonográfico e radiográfico que evidenciou aumento do diâmetro das alças intestinais e imagem sugestiva de intussuscepção. $O$ paciente foi encaminhado para laparotomia exploratória de urgência e obteve o diagnóstico definitivo de intussuscepção ileocólica associada a torção mesentérica. Devido a extensão do comprometimento intestinal foi optado pela eutanásia do paciente na mesa cirúrgica.
\end{abstract}

Palavras-chave: abdômen agudo; choque circulatório; cirurgia intestinal

\section{ILEOCOLIC INTUSSUSCEPTION ASSOCIATED WITH MESENTERIC TORSION IN DOG: CASE REPORT}

\begin{abstract}
Mesenteric torsion is a rare disease in dogs whereas it is more common to affect large animals. The main clinical signs observed are acute, such as prostration and abdominal distension which evolve to a state of shock and death. This paper reports the mesenteric torsion in a dog that was presented to veterinary care with generalized acute abdominal pain of sudden onset. At the physical examination, signs of acute abdomen, rectal temperature of $35^{\circ} \mathrm{C}$, moderate dehydration, congested mucous membrane, and prostration were detected. Emergency therapy was instituted and radiographic and ultrasound examinations were requested. The radiography showed increase in the bowel diameter and an image suggestive of intussusception. The patient was referred to emergency exploratory laparotomy and obtained a definite diagnosis of ileocolic intussusception associated to mesenteric torsion. Due to the extent of intestinal dysfunction, the patient was euthanized on the operating table.
\end{abstract}

Key Words: acute abdomen; circulatory shock; intestinal surgery 


\section{INTRODUÇÃO}

A torção de mesentério é uma patologia rara, aguda e esperadamente fatal em cães. É uma condição incomum em cães, com a predisposição na raça pastor alemão (Cairo, 1999) e está descrita com maior incidência em cães machos, de idades compreendidas entre os dois e os três anos, havendo também registros em animais de raças miniatura (Camble e Page, 1992). Apresenta um prognóstico grave, sendo geralmente fatal com uma taxa de mortalidade muito elevada que ronda os 100\% (Matushek e Cockshutt, 1987).

Anatomicamente, as áreas do intestino que não estão fixadas em posição por ligamentos ao peritônio parietal ou víscera adjacente são sustentadas pelo mesentério, o qual permite grande liberdade de movimento (Headlund e Fossum, 2008). $\mathrm{Na}$ fisiopatologia da doença, o intestino se torce em torno de seu eixo mesentérico, resultando em obstrução mecânica estrangulante do intestino delgado, e compressão da artéria mesentérica cranial e seus ramos. Veias e vasos linfáticos primeiramente se obstruem resultando em edema e ingurgitamento vascular da parede intestinal (Brown, 2003), levando a obstrução vascular e congestão venosa do duodeno distal, jejuno, íleo, ceco, colon ascendente, e colon descendente proximal (Nemzek, 1993). Geralmente, o jejuno é a porção mais acometida (Headlund e Fossum, 2008). Como consequência do comprometimento vascular e necrose intestinal, ocorre a subsequente liberação de toxinas, levando ao choque (Dow et al., 1989). A seguinte cascata de obstrução vascular, anóxia tecidual, choque circulatório, endotoxemia e insuficiência cardíaca resultam na morte se a condição não for corrigida imediatamente (Headlund e Fossum, 2008). O prognóstico é ruim a sombrio devido à bacteremia que ocorre como resultado da translocação bacteriana através da mucosa intestinal isquêmica (Dow et al., 1989). Quando a torção persiste, ocorre hipóxia da parede do intestino afetado, resultando em destruição da barreira da mucosa, permitindo a translocação bacteriana e de toxinas difundindo-se para a cavidade peritoneal. A maioria das lesões ocorrem quando este tecido é reperfundido, resultando em injúria de reperfusão (Junius et al., 2004).

A maioria dos casos de torção de mesentério não tem causa identificada. Atividade vigorosa, dieta inadequada ou trauma muitas vezes precedem 0 vólvulo (Headlund e Fossum, 2008). Anormalidades na motilidade gastrointestinal secundária a desordens como insuficiência pancreática exócrina (particularmente em pastores alemães), doença intestinal inflamatória, intussussepção ileocólica, síndrome dilatação vólvulo gástrica, e corpos estranhos gastrointestinais podem predispor um cão a torção mesentérica (Shealy e Henderson, 1992). Em humanos, esta patologia é rara e pode ser primária ou secundária a uma anormalidade anatômica como neoplasias ou aderências (Huang et al., 2005).

As causas mais comuns de abdômen agudo em cães incluem gastrite, pancreatite e obstruções por corpos estranhos gastrointestinais; também deve-se diferenciar peritonite, intussussepção e raramente a torção mesentérica (Hughes 2005). Muitas etiologias da torção mesentérica têm sido sugeridas, incluindo desverminação, enterite linfocíticaplasmocítica, carcinoma ileocólico, insuficiência pancreática, infecção por parvovírus, exercício vigoroso, trauma abdominal fechado, concomitante dilatação gástrica e torção, e corpos estranhos gástricos. Entretanto, a maioria dos casos é idiopática (Junius et al., 2004). Nemzek et al. (1993) 
registraram um caso de torção de mesentério associado a desverminação, mas outras associações têm sido observadas, nomeadamente: a ingestão de grandes quantidades de alimento num curto espaço de tempo, o exercício vigoroso, o trauma abdominal, a cirurgia abdominal e a presença de corpos estranhos gastrointestinais (Matushek e Cockshutt, 1987).

$\mathrm{Na}$ torção de mesentério não há apresentação de sinais clínicos patognomônicos, embora geralmente os animais acometidos apresentem fraqueza, prostação e choque em casos agudos (Shealy e Henderson, 1992). Eles também podem apresentar histórico de vômito, hematêmese, hematoquezia (Cosenza, 1996), dor e distensão abdominal (Junius et al., 2004). Para Brown (2003), os sinais clínicos são hiperagudos e agudos; distensão abdominal geralmente progressiva e hematoquezia são descritas com mais frequência.

O diagnóstico pode ser desafiador, porque os sinais clínicos são inespecíficos e a condição é rapidamente progressiva. Normalmente, quando um animal é atendido em choque com distenção abdominal gasosa que não é aliviada pela sonda orogástrica, o veterinário deve suspeitar de torção mesentérica (Brown, 2003). Radiografias abdominais geralmente demonstram distensão do intestino delgado e diminuição dos detalhes abdominais (Cosenza, 1996).

Qualquer causa sistêmica ou mecânica de abdômen agudo deve ser incluída no diagnóstico diferencial como dilatação vólvulo gástrica, vólvulo cecocólico, torção e ruptura esplênica, obstrução mecânica, trauma abdominal, peritonite, gastroenterite hemorrágica, enterites virais e pancreatite (Headlund e Fossum, 2008). O tratamento consiste na reanimação rápida com fluidoterapia cristalóide e colóide para terapia do choque e proporcionar cirurgia imediata para redução da torção (Brown, 2003).

O presente trabalho relata o caso clínico de um paciente com torção mesentérica, descreve a gravidade da patologia que impossibilitou o sucesso cirúrgico devido à extensão da mesma.

\section{RELATO DE CASO}

Apresentou-se para atendimento emergencial, um cão da raça Teckel com 5 anos de idade, $8 \mathrm{~kg}$ de peso corporal, com histórico de dor abdominal aguda progressiva, com início de aproximadamente 12 horas, associado a prostação e anorexia. Ao exame físico o animal apresentava-se em quadro apático, temperatura retal de 35 graus Celsius, desidratação moderada, mucosas congestas, tempo de preenchimento capilar 2 segundos e intensa dor abdominal à palpação, o qual encontrava-se abaulado e a percussão apresentava-se timpânico. A auscultação revelou frequência cardíaca de 130 batimentos por minuto, e frequência respiratória de 44 movimentos por minuto. Os dados da anamnese eram escassos, e o proprietário apenas relatou como anormalidade apetite depravado como hábito, desde filhote, mas sem histórico de outras patologias ou intervenção cirúrgica. Foram colhidas amostras sanguíneas para realização de avaliação laboratorial e instituída terapia de suporte, com fluidoterapia intravenosa com Ringer lactato, enriquecida com potássio, butorfanol 0,4 $\mathrm{mg} / \mathrm{kg}$ por via intramuscular e aquecimento do animal, e encaminhado para o setor de diagnóstico por imagem. $A$ radiografia evidenciou aumento do diâmetro das alças intestinais, com presença de gás em toda sua extensão (Figura 1), e a ultrassonografia revelou imagem em aparência de alvo, com camadas múltiplas (Figura 2) sugerindo intussuscepção. 


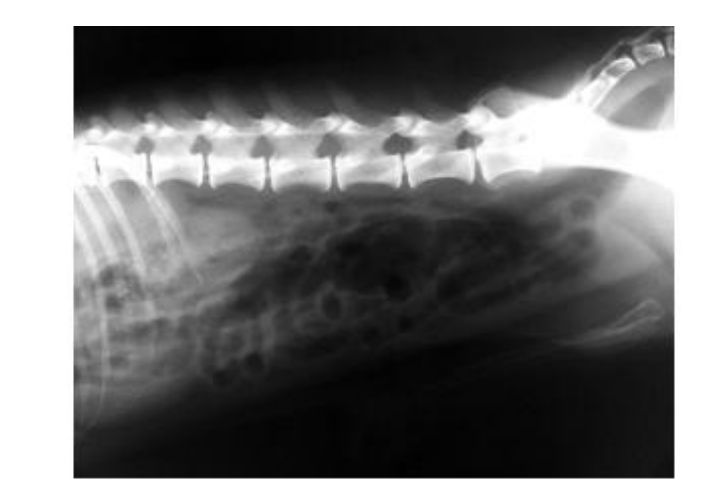

Figura 1. Alças intestinais repletas de gás em toda sua extensão.

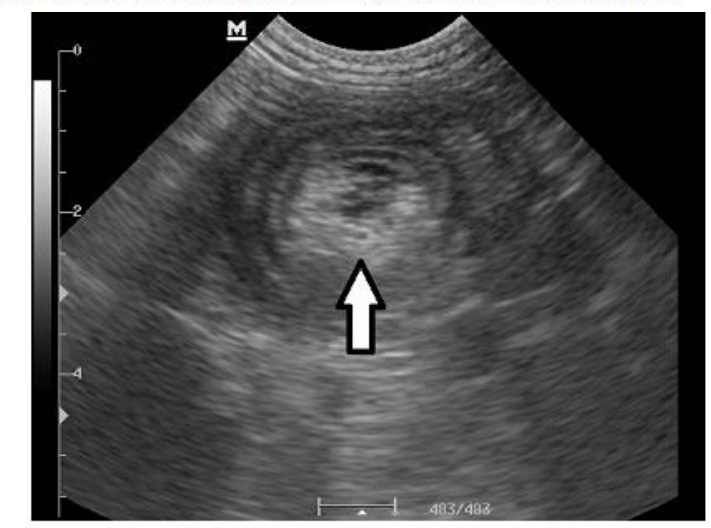

Figura 2-Ultrassonografia abdominal revelando imagem compativel com intussuscepção (seta): aparência em forma de alvo com camadas múltiplas (anéis hiperecóicos e hipoecóicos concêntricos).

Os exames laboratoriais revelaram ausência de alterações em séria vermelha, leucocitose absoluta por neutrofilia moderada, e proteínas plasmáticas totais discretamente elevadas. Diante do quadro clínico de abdômen agudo, e sinais clínicos sugestivos de choque circulatório e possível intussuscepção, o paciente foi encaminhado para laparotomia exploratória de urgência. $O$ animal foi mantido na fluidoterapia já descrita, e complementado com outro acesso para infusão de solução coloidal hetamido. 0 protocolo anestésico utilizado foi midazolam por via intramuscular na dose $0,3 \mathrm{mg} / \mathrm{kg}$ e após quinze minutos induzido com propofol na dose de 4 $\mathrm{mg} / \mathrm{kg}$ intravenoso e mantido com inalação de isofluorano. $O$ acesso cirúrgico iniciou-se com uma incisão mediana ventral desde o processo xifóide até a entrada do púbis, expondo toda a cavidade abdominal, e ao acessá-la, foi possível observar todas as alças intestinais, tanto do intestino delgado quanto grosso, distendidas por gás, a serosa apresentando-se totalmente enegrecida, os vasos do mesentério congestos (figura $3-\mathrm{A}$ ) e ausência de motilidade. Ao correrem-se os segmentos intestinais foi encontrada a intussuscepção ileocólica (figura 3-B).

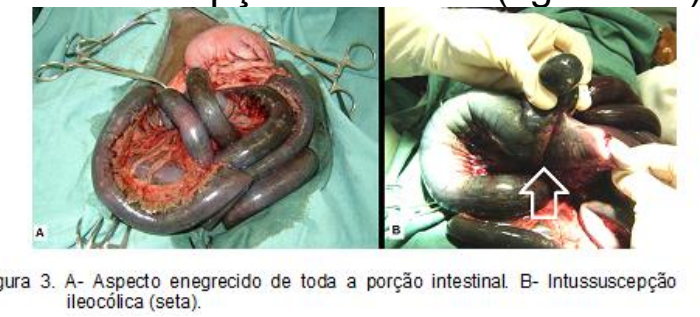

Foi possível visualizar a rotação no sentido horário ao longo do eixo longitudinal do pedículo mesentérico, e desta forma, concluiu-se como diagnóstico definitivo de intussuscepção ileocólica associada a torção mesentérica completa, observando a isquemia de toda a porção intestinal. Devido ao comprometimento intenso e extenso das porções intestinais, impossibilitando a ressecção das áreas inviáveis, e o risco de lesão de reperfusão, foi optado pela eutanásia do paciente na mesa cirúrgica, de modo a isentá-lo de sofrimento complementar.

\section{DISCUSSÃO}

A torção de mesentério geralmente evolui para choque e óbito como foi relatado no presente caso. Para Headlund e Fossum (2008), tratase de uma emergência clínica e cirúrgica, e é sabido que o pronto atendimento de urgência melhora 0 prognóstico, mas não há garantia de sobrevida, pois ressalta-se que a mortalidade aproxima-se de 100\%.

A provável causa da patologia neste paciente foi o apetite depravado, que culminou em hipermotilidade, e que persistente, levou a intussuscepção e a torção mesentérica. Assim como descrito por Headlund e Fossum (2008), os cães jovens adultos são mais comumente acometidos. Cicco et al., (2011) relataram um caso de torção mesentérica em um paciente, também 
da raça Teckel, com sinais clínicos semelhantes: letargia, desconforto, arqueamento dorsal e dor abdominal. Diagnosticaram múltiplos corpos estranhos na região gástrica através de radiografia abdominal, e a laparotomia exploratória revelou torção mesentérica como patologia associada a obstrução gástrica.

Knell et al.,( 2010) descreveram o relato de dois felinos apresentando torção mesentérica. O diagnóstico foi realizado rapidamente e o procedimento cirúrgico indicado. A realização de enterectomia seguida de enteroanastomose foi bem sucedida. Mas diferentemente do presente caso, a porção intestinal comprometida foi, em um paciente do jejuno a junção cecocólica, e no outro paciente da metade do jejuno ao íleo, permitindo a ressecção, assim como nos relatos descritos por Rahal et al., (2000) e Soares et al., (2007), em que ambos pacientes apresentaram a torção apenas do intestino delgado, comprometendo apenas uma porção deste, o que novamente, possibilitou a ressecção. No paciente deste presente relato não havia tecido viável que possibilitasse a ressecção. É importante ressaltar que em todos esses casos de sucesso os pacientes apresentaram no pós cirúrgico de forma persistente, síndrome do intestino curto.

Spevakow et al., (2010) em um relato de caso, concluíram o diagnóstico final da torção mesentérica com laparotomia exploratória, com resultados positivos. Neste trabalho, os autores descreveram um caso incomum, um paciente canino que apresentava vômitos e diarreia, mas de forma crônica. O paciente em questão não apresentou choque, dor abdominal e distensão, sinais esperados nesta patologia. É importante reafirmar que também neste caso, cuja terapia cirúrgica foi bem sucedida, as alças intestinais apresentaram mínima congestão, com sinais de inviabilidade em uma porção que era possível realizar a enterectomia/ enteroansatomose.

A laparotomia exploratória foi realizada seguindo o que sugere a literatura, que afirma que quando a anamnese, os sinais clínicos e o diagnóstico por imagem sugerem fortemente uma obstrução intestinal, há a indicação de uma laparotomia exploratória imediata (Parker e Presnell, 1972; Walshaw, 1989). De fato, o diagnóstico definitivo surge na cirurgia ou na necrópsia (Shealy e Henderson, 1992; Shahar et al.,1998), Vieira et al., (2008), conforme foi constatado neste caso. Corroborando com estes dados, Kik e Linde-Sipman (1993) descreveram dez casos de torção de mesentério, sendo que apenas um foi diagnosticado clinicamente sendo os restantes achados de necrópsia.

Para Brown (2003) infelizmente tão logo o diagnóstico fica óbvio nas radiografias, a maior parte do trato intestinal está isquêmica e necrosada, e os animais estão destinados a morrer ou a sofrer eutanásia, conforme foi visto neste paciente. Não se conhecem fatores objetivos de prognóstico positivo e o sucesso terapêutico parece ser fortuito (Shealy e Henderson, 1992). Estão associados de forma subjetiva a uma maior taxa de sucesso, a rapidez de diagnóstico, a extensão de ressecção intestinal, a torção limitada a um ângulo de rotação menor ou igual a $180^{\circ}$ e uma intervenção cirúrgica rápida (Shealy e Henderson, 1992; Brown, 2003), sendo que o diagnóstico e a intervenção cirúrgica imediata não foram suficientes para obter-se sucesso no paciente deste relato.

\section{CONCLUSÃO}

A torção de mesentério é uma doença de prognóstico sombrio, e 
quando existem evidências nos sinais clínicos e nas imagens radiográficas e ultrassonográficas, o cirurgião deve encorajar-se na realização da laparotomia exploratória, o que pode aumentar a taxa de sobrevida nestes pacientes, quando há possibilidade de ressecção intestinal, o que infelizmente não foi possível neste paciente.

\section{REFERÊNCIAS}

BROWN, D.C. Intestino delgado. In: SLATTER. Manual de Cirurgia Veterinária. 3 ed. Elsevier, 2003. Cap.41, p.660-661.

CAIRO, J, et al. Intestinal volvulus in dogs: a study of four clinical cases. Journal of Small Animal Practice, v.40, n.3, p.136-140, 1999.

CAMBLE, P.J.; PAGE, C.A. Mesenteric torsion in a toy dog. The Veterinary Record, v.13, n.12, p.283-284, 1992.

CICCO, M.F.D. et al. Segmental Jejunal Entrapment, Volvulus, and Strangulation Secondary to Intra-abdominal Adhesions in a Dog- Case report. Journal of American Animal Hospital Association, v.47, n.1, p.3135, 2011.

COSENZA, S.F. Recognizing and treating mesenteric torsion in dogs. Veterinary Medicine, v.6, p.926-933,1996.

DOW, S.W. et al. Bacterial culture of blood from critically ill dogs and cats: 100 cases (19851987). Journal of American Veterinary Medical Association, v.195, n.1, p.113-117, 1989.

HEADLUND, C.S.; FOSSUM, T.W. Cirurgia do Sistema Digestório- Vôlvulo e Torção Intestinais. In: FOSSUM, T.W. Cirurgia de Pequenos

Animais, Elsevier, 2008. Cap. 19, p.477-480.

HUANG, J.C.; SHIN, J.S.; HUANG, Y.T. Small bowel volvulus among adults. Journal of

Gastroenterology and Hepatology, v.20, n.12, p.1906-1912, 2005.

HUGHES, D. Acute abdomen. In: ETTINGER S.J.; FELDMAN E.C. Textbook of veterinary internal medicine. 6th ed. St. Louis (MO): Elsevier; 2005: p.401-4.

JUNIUS, G. et al. Mesenteric volvulus in the dog: A retrospective study of 12 cases. Journal of
Small Animal Practice, v.45, n.2, p.104-107, 2004.

KIK, M.J.; LINDE-SIPMAN, J.S. Mesenterial torsion in dogs. Tijdschr Diergeneeskd, v.118, n.4, p.115-116, 1993.

KNELL, S.C. et al. Successful treatment of small intestinal volvulus in two cats. Journal of Feline Medicine and Surgery, v.12, p.874-877, 2010.

MATUSHEK, K.J.; COCKSHUTT, J.R. Mesenteric and gastric volvulus in a dog. Journal of the American Veterinary Medical Association, v.191, n.3, p.327-328, 1987.

NEMZEK, J.A.; WALSHAW, R.; HAUPTMAN, J.G.; Mesenteric volvulus in the dog: A retrospective study. Journal of the American Animal Hospital Association, v.29, p.357-362, 1993.

PARKER, W.M.; PRESNELL, K.R. Mesenteric torsion in the dog: two cases. Canadian Veterinary Journal, v.13, n.12, p.283-284, 1972.

RAHAL, S.C. et al. Mesenteric torsion in a dog. The Canadian Veterinary Journal, v.41, p.410411, 2000.

SHAHAR, R.; HARRUS, S.; YAKOBSON, B. Mesenteric vein thrombosis in a dog. Journal of American Hospital Association, v.34, n.5, p.431-433, 1998.

SHEALY, P.M.; HENDERSON, R.A. Canine intestinal volvulus: A report of nine new cases. Veterinary Surgery, v.21, n.1, p.15-19, 1992.

SOARES, T.F. et al. Torção de mesentério-um caso clínico. Revista Portuguesa de Ciências Veterinárias, v.102, n.563-564, p.355-360, 2007.

SPEVAKOW, A.B. et al. Chronic mesenteric volvulus in a dog- Case report. The Canadian Veterinary Journal, v.50, p.85-88, 2009.

VIEIRA, F.V. et al. Torção intestinal em cão: relato de caso. Veterinária e Zootecnia, v.15, n.2, p.110, 2008.

WALSHAW, R. What is your diagnosis? Journal of the American Veterinary Medical Association, v.194, n.11, p.1631-1632, 1989. 